\title{
Perch Selection by Three Cooccurring Species of Celithemis (Odonata: Libellulidae): Testing for a Competitive Hierarchy among Similar Species
}

\author{
Wade B. Worthen and Parker H. Morrow \\ Biology Department, Furman University, Greenville, SC 29613, USA \\ Correspondence should be addressed to Wade B. Worthen; wade.worthen@furman.edu
}

Received 25 April 2016; Revised 12 August 2016; Accepted 28 August 2016

Academic Editor: G. B. Dunphy

Copyright (C) 2016 W. B. Worthen and P. H. Morrow. This is an open access article distributed under the Creative Commons Attribution License, which permits unrestricted use, distribution, and reproduction in any medium, provided the original work is properly cited.

\begin{abstract}
In many communities of perching dragonflies (Odonata: Libellulidae), a size-dependent competitive hierarchy creates a positive relationship between male body size and perch height. We tested for this pattern among three similar-sized species: Celithemis elisa, C. fasciata, and C. ornata. Males were caught and photographed from May to July 2015 at Ashmore Heritage Preserve, Greenville County, SC, USA, and perch heights and perch distance to open water were measured. Five indices of body size were measured with ImageJ software: abdomen length, forewing length, hindwing length, area of forewing, and area of hindwing. Celithemis fasciata was significantly larger than the other two species for all five anatomical characters and used perches that were significantly taller and closer to open water than the other species, though these differences changed over the summer. Aggressive interactions between and within species were tallied and compared to expected distributions based on mean relative abundances derived from hourly abundance counts. Patterns of interspecific aggression were also consistent with a size-dependent hierarchy: the large $C$. fasciata was attacked less frequently, and the small C. ornata more frequently, than predicted by their relative abundances. We conclude that even small differences in body size may contribute to niche partitioning in perch selection.
\end{abstract}

\section{Introduction}

In general, large size confers a competitive advantage to animals engaged in physical combat [1-3]. As a consequence of greater strength and the application of greater force, larger animals are more likely to win contests for mates, territories, and other resources [2,3]. Many dragonfly (order: Odonata) species are highly aggressive and territorial [4]; males perch on vegetation along the periphery of a water body and defend small territories around oviposition sites, driving off other males and attempting to mate with passing females. Appropriate perch selection has important benefits for reproductive success [5-8], and size-dependent hierarchies occur in both intraspecific and interspecific patterns of territory acquisition and perch selection.

In Pachydiplax longipennis, for example, larger males are typically the aggressor in intraspecific interactions, forcing smaller males to disperse [9]. In several other species, males holding territories either are larger than "satellite" males without territories (suggesting a size advantage for acquiring territories) or win more intraspecific contests [1014]. However, because body size differences within a species are often small, other factors like age, fat reserves, or sexual ornamentation can be more important than size to the outcome of a particular competitive battle [15]. Residency itself can provide a competitive advantage; territory owners are more likely to win contests than challengers, perhaps because of the competitive edge that earned them the territory in the first place or their greater familiarity with the site $[4,16-20]$.

Competitive hierarchies also exist between species, particularly with respect to perch selection. Because perches are used to survey territories for food, mates, predators, and intruders, maximum visibility is probably a key component of perch quality [21]. Tall perches provide better visibility than short perches, particularly as the distance from open water increases and the view from short perches is obstructed by 
intervening vegetation. As predicted, competitively dominant large species use tall perches and relegate progressively smaller species to progressively shorter perches [22-27]. Perithemis tenera, a small species $(20 \mathrm{~mm})$, uses short perches $(<20 \mathrm{~cm})$ but maximizes visibility by selecting perches that are beyond the shoreline in open water [21].

There are exceptions to these patterns, however, usually among closely related species that are similar in size. For example, Sympetrum flaveolum is slightly larger than Sympetrum sanguineum but uses shorter perches, probably as a consequence of exploiting earlier successional habitats with shorter vegetation [28]. In competitive interactions among closely related similar-sized species, the same factors that affect intraspecific competition may become important, like age, fat reserves, or residency [15]. Residency is a stronger predictor of competitive success than size in competitive interactions among five species of Erythrodiplax [29]. When size differences between species are small or inconsistent, size-dependent differences in perch height alone may not be enough to promote coexistence; selection may favor resource partitioning along additional niche dimensions like seasonality [30], diel period [31, 32], habitat [28, 33], or another characteristic of the perch like distance from shore [21].

The genus Celithemis provides an ideal model system for examining these relationships. All of the eight species of Celithemis occur in the Eastern United States [34], with a narrow size range from Celithemis amanda (22 $\mathrm{mm}$ body length) to Celithemis eponina (38 mm) [35]. Most ponds and marshes in the region will harbor at least 2-3 species, particularly in southeastern states where as many as five Celithemis species can co-occur [36]. Lastly, Celithemis elisa, C. fasciata, and C. ornata are territorial; they exhibit both "site attachment" and "agonistic defense" [37]. This study had three objectives: (i) compare the body sizes of Celithemis elisa, C. fasciata, and $C$. ornata males and determine if patterns of perch selection (based on perch height and the distance of perches from open water) correlate with differences in body size; (ii) describe patterns of diel and seasonal activity to determine whether these species partition resources temporally; and (iii) describe patterns of intra- and interspecific aggression among these species to determine whether the patterns of spatial and temporal perch selection are consistent with a size-dependent competitive hierarchy.

\section{Materials and Methods}

2.1. Study Site. This research was conducted at Lake Wattacoo at the Ashmore Heritage Preserve, Greenville County, SC, USA (latitude: $35^{\circ} 5^{\prime} 6.83^{\prime \prime} \mathrm{N}$, longitude: $82^{\circ} 34^{\prime} 43.64^{\prime \prime} \mathrm{W}$, elevation $347 \mathrm{~m}$ ). The lake is a 2.2 ha impoundment on the 455 ha preserve, directly below the southeastern escarpment of the Blue Ridge Mountains [38]. The lake is bordered on two sides by mixed oak-pine woodlands. The study was conducted along $200 \mathrm{~m}$ of treeless lakeshore on the earthen dam. The steep slope of the dam limits rooted macrophytes to a zone of reeds extending 1-2 $\mathrm{m}$ from the bank. These reeds and the shoreline vegetation were used as perches by territorial male dragonflies. Celithemis elisa (Hagen), Celithemis fasciata Kirby, and Celithemis ornata (Rambur) are the most abundant libellulids at the site, constituting $85 \%$ of the libellulid individuals in a 2014 survey [39]. The most common species in the region, Pachydiplax longipennis (Burmeister), Libellula incesta Hagen, and Erythemis simplicicollis (Say), are present but uncommon at Wattacoo, so interactions among Celithemis species can be studied without the complicating effects of other species.

2.2. Sampling Protocol. Sampling was conducted from May to July 2015, 3-4 days/week, in 3-6-hour blocks of rainless conditions, between $1000 \mathrm{~h}$ and $1600 \mathrm{~h}$. At the stroke of each hour, the $200 \mathrm{~m}$ dam was walked twice ("out" and "back" transects); the number of individuals of each species seen on each transect was counted, and the counts were averaged to compute an hourly abundance for each species. Between these hourly counts, we randomly shifted our activity between collecting males for body size measurements, measuring perch heights of territorial males, and observing aggressive interactions. These activities were done at different times in different areas on different males, so that our swinging nets and measuring perches would not disturb observations. Males were collected by aerial net, numbered on their wing with a Sharpie ${ }^{\odot}$ marker for identification (and to prevent resampling), photographed with a ruler for scale, and released. Males were collected at the shoreline and along the bank, so both territory holders and satellite males were collected and measured. For territorial perches used by males, the vertical height and horizontal distance to open water were measured. Perches were considered "territorial" if they were along the shoreline (not on the bank) or on emergent vegetation. Aggressive interactions were scored by observing a target area (approximately $5 \mathrm{~m}$ of shoreline that contained perched dragonflies) for 15-30 minutes and recording as many interactions as possible. An "attack" was scored when a perched dragonfly was attacked by another dragonfly. A "sortie" was scored when a perched dragonfly left the perch to charge a passing dragonfly and return to its perch. A "chase" was scored when one dragonfly pursued another. The interactions can be rapid and dynamic; a perched dragonfly might be attacked, initiate a sortie against the attacker, and then be chased in an ensuing dogfight [40]. Each of these three interactions was scored separately, noting the species of the aggressor and target for each.

\subsection{Testing the Relationship between Body Size and Perch} Selection. Five attributes of body size were measured on each dragonfly photograph using ImageJ software [41]: length and area of forewing, length and area of hindwing, and abdomen length. Variations in these parameters between species were assessed and described with MANOVA, ANOVA, and Tukey mean comparison tests. Variations between species and across months in perch height and distance from perch to open water were assessed with two-way factorial ANOVA and Tukey mean comparison tests and compared with predictions based on a size-dependent competitive hierarchy.

2.4. Testing for Patterns of Temporal Partitioning. Variations between species, across diel period, and across months 
TABLE 1: Summary of ANOVA describing the variation in five anatomical characters between male Celithemis ornata, C. elisa, and C. fasciata collected from May to July 2015 at Ashmore Heritage Trust Preserve, Greenville County, USA: length of forewing, length of hindwing, abdomen length, area of forewing, and area of hindwing.

\begin{tabular}{lcccccc}
\hline \multirow{2}{*}{ Character } & \multicolumn{2}{c}{ Species effect } & \multicolumn{2}{c}{ Error } & \multirow{2}{*}{$F$} & $P$ \\
& df & MS & df & MS & & \\
\hline Forewing length & 2 & 50.258 & 218 & 3.799 & 13.230 & 0.0001 \\
Hindwing length & 2 & 46.499 & 218 & 3.647 & 12.748 & 0.0001 \\
Abdomen length & 2 & 41.602 & 218 & 2.632 & 15.809 & 0.0001 \\
Forewing area & 2 & 6265.947 & 218 & 436.550 & 14.353 & 0.0001 \\
Hindwing area & 2 & 9789.665 & 218 & 636.533 & 15.380 & 0.0001 \\
\hline
\end{tabular}

in mean hourly abundances were assessed with three-way factorial ANOVA and Tukey mean comparison tests.

2.5. Testing for a Size-Dependent Competitive Hierarchy. The observed frequencies with which each Celithemis species engaged the three species in each interaction were pooled across the entire sampling period. For each behavior (attack, sortie, and chase), we compared the frequencies at which each species acted aggressively towards each of the three species. To determine whether a species preferred or avoided acting aggressively towards another species, we compared these observed values with frequencies we would expect if there was no preference. If a species shows no preference or avoidance, it should engage target species at the same proportions as the species occur in the environment. We computed the proportional representation of each species in the environment by (i) calculating the mean hourly abundance values averaged over the entire sampling period; (ii) totaling these means; and (iii) computing the proportional representation of each species to this total. For each contrast, expected values were generated by multiplying the total number of observations for that contrast by these proportions. Observed and expected values were compared with chisquare goodness of fit tests. All statistical tests were conducted using SPSS software [42].

\section{Results}

3.1. Relationships between Body Size and Perch Selection. There were statistically significant differences among these three study species in the five attributes of body size, whether patterns are analyzed concurrently (MANOVA, Wilk's $\lambda, F=$ $8.173, \mathrm{df}=10,428, P<0.0001)$ or in separate ANOVA (Table 1). For each of the five attributes, C. fasciata was significantly larger than the other two species (Figure 1). Although C. elisa was larger than C. ornata in four of the five variables (not abdomen length), none of these differences were statistically significant (Figure 1).

There were statistically significant differences between species for both perch height and the distance from the perch to open water ("species" effect, Tables 2(a) and 2(b)). Overall, C. ornata used perches that were significantly shorter than those used by the other two species, while C. fasciata used

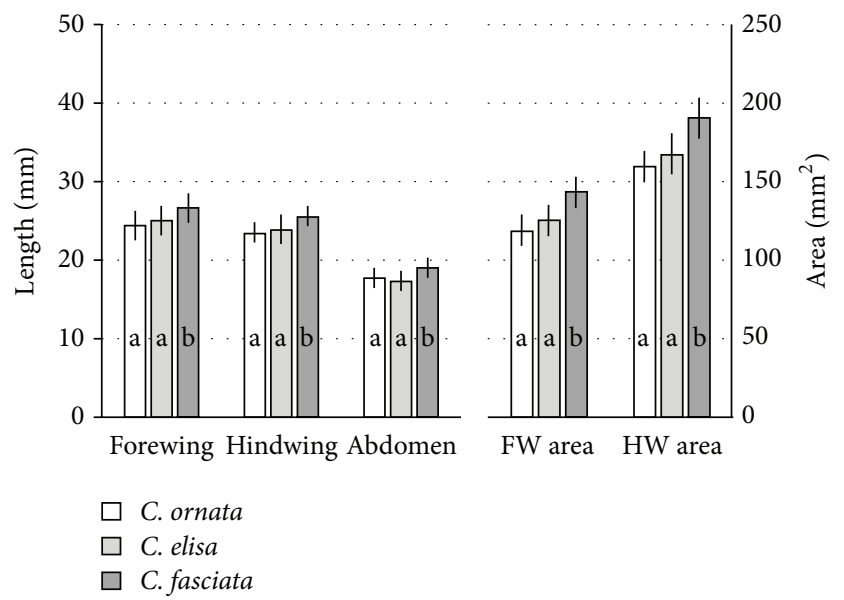

FIGURE 1: Mean comparisons of five body size indicators between males of Celithemis ornata $(N=51)$, C. elisa $(N=139)$, and C. fasciata $(N=31)$ collected at Ashmore Heritage Preserve, Greenville County, SC, USA, from May to July 2015. Mean ( \pm SD) lengths of forewing, hindwing, and the abdomen and the area of forewing (FW area) and hindwing (HW area) were compared. For each attribute, species labeled with the same letter are not significantly different (Tukey mean comparison tests, $P=0.05$ ).

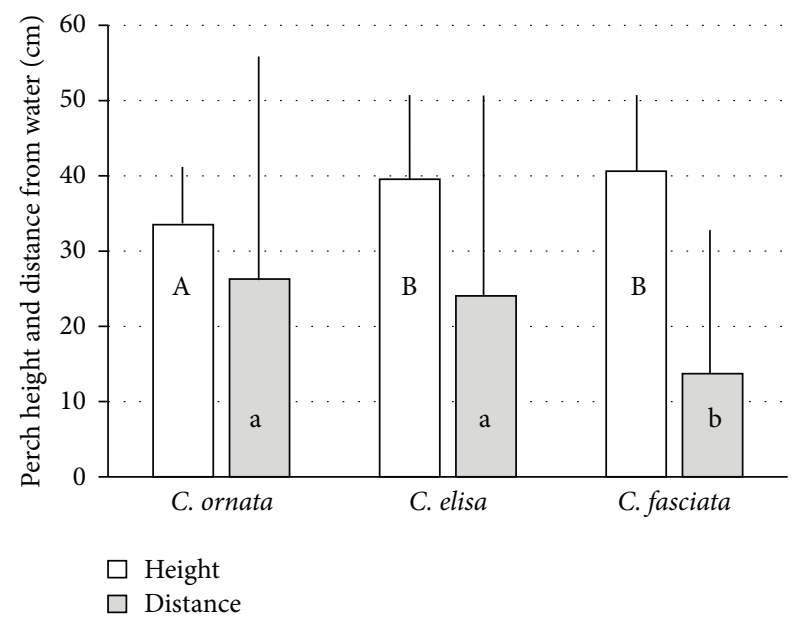

FIGURE 2: Mean (+SD) perch height and distance from open water $(\mathrm{cm})$ for perches used by male Celithemis ornata $(N=278)$, C. elisa $(N=331)$, and C. fasciata $(N=207)$ at Ashmore Heritage Preserve, Greenville County, SC, USA, from May to July 2015. For each variable, species labeled with the same letter are not significantly different (Tukey mean comparison tests, $P=0.05$ ).

perches that were significantly closer to water (Figure 2). Mean perch height tended to increase over the summer while perch distance from the water tends to decrease ("month" effect, Tables 2(a) and 2(b)). These trends, however, were not consistent across species ("species $\times$ month" effect, Tables $2(\mathrm{a})$ and 2(b)). Mean perch height of C. elisa increased by $12 \mathrm{~cm}$ over the summer, which was twice the increase of the other two species (Figure 3(a)). Likewise, although $C$. ornata and C. elisa perched closer to the water as summer 


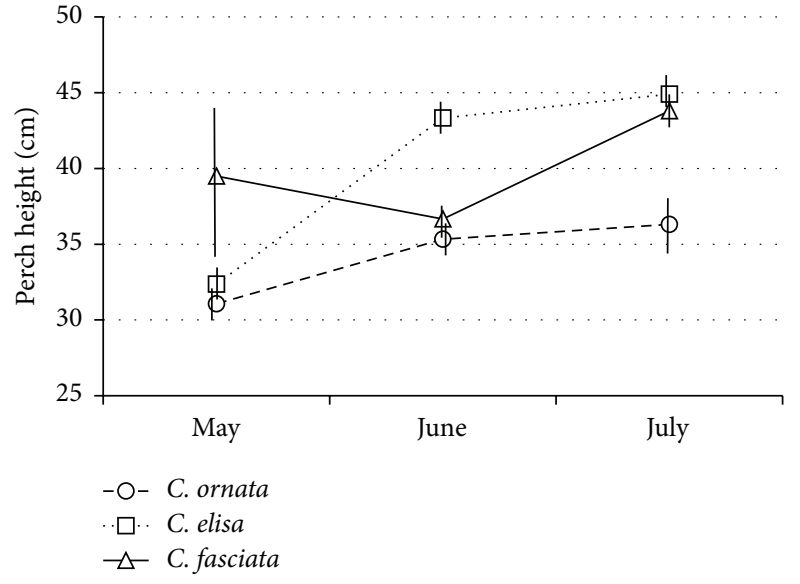

(a)

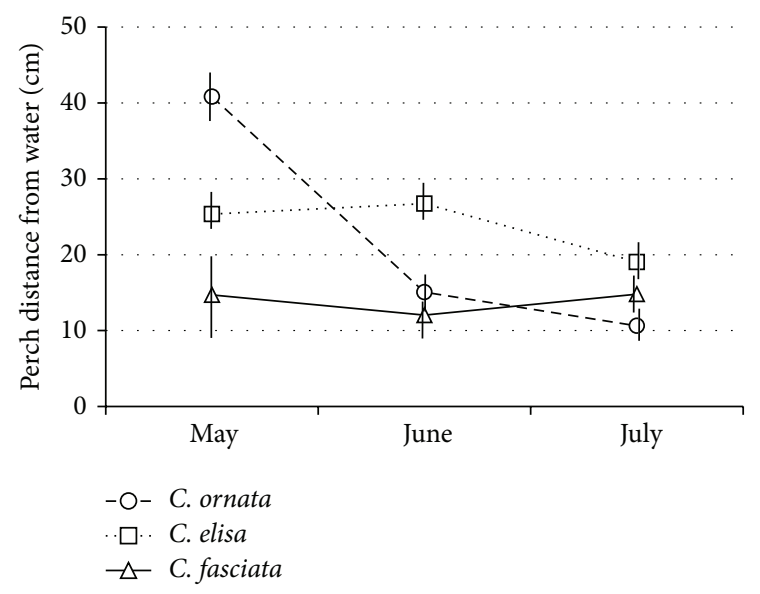

(b)

FIGURE 3: Monthly changes in (a) perch height (mean \pm SE) and (b) perch distance from open water (mean \pm SE) for Celithemis ornata, C. elisa, and C. fasciata at Ashmore Heritage Preserve, Greenville County, SC, USA.

TABLE 2: ANOVA describing the direct and interactive effects of species ("species") and sampling period ("month") on (a) perch height and (b) perch distance from open water, for males of Celithemis ornata, C. elisa, and C. fasciata at Ashmore Heritage Trust Preserve, Greenville County, USA.

(a)

\begin{tabular}{lccccc}
\hline Source & df & Type III SS & MS & $F$ & $P$ \\
\hline Species & 2 & 5475.492 & 2737.746 & 28.709 & 0.0001 \\
Month & 2 & 4684.503 & 2342.251 & 24.561 & 0.0001 \\
Species $\times$ month & 4 & 3613.844 & 903.461 & 9.474 & 0.0001 \\
Error & 807 & 76958.345 & 95.364 & & \\
\hline
\end{tabular}

(b)

\begin{tabular}{lccccc}
\hline Source & df & Type III SS & MS & $F$ & $P$ \\
\hline Species & 2 & 9028.425 & 4514.212 & 6.108 & 0.002 \\
Month & 2 & 12965.444 & 6482.722 & 8.772 & 0.0001 \\
Species $\times$ month & 4 & 29343.458 & 7335.865 & 9.926 & 0.0001 \\
Error & 807 & 596397.391 & 737.030 & & \\
\hline
\end{tabular}

progressed, C. fasciata tended to perch near the water throughout the sampling period (Figure 3(b)).

3.2. Patterns of Temporal Partitioning. There was a significant difference in the mean hourly abundances of these three species overall ("species" effect, Table 3); on average, C. elisa (mean $\pm 1 \mathrm{SE}=13.34 \pm 0.65, N=178$ ) was significantly more abundant than C. fasciata $(7.34 \pm 0.63, N=178)$ and $C$. ornata $(6.56 \pm 0.39, N=178)$ which did not differ from one another (Tukey mean comparison test, $P=0.05$ ). However, these patterns changed significantly over the course of the summer ("species $\times$ month" effect, Table 3 ). While $C$. elisa maintained a consistently high abundance throughout the summer, C. ornata abundance declined and C. fasciata abundance increased as summer progressed (Figure 4). There was also a significant change in abundance over the course of
TABLE 3: ANOVA describing the direct and interactive effects of species ("species"), diel period ("hour"), and sampling period ("month") on the mean abundance of Celithemis ornata, C. elisa, and C. fasciata at Ashmore Heritage Trust Preserve, Greenville County, USA, from May to July 2015.

\begin{tabular}{lccccc}
\hline Source & df & Type III SS & MS & $F$ & $P$ \\
\hline Species & 2 & 2722.832 & 1361.416 & 33.577 & 0.0001 \\
Hour & 6 & 2826.822 & 471.137 & 11.620 & 0.0001 \\
Month & 2 & 96.338 & 48.169 & 2.830 & 0.024 \\
Species $\times$ hour & 12 & 521.047 & 43.421 & 1.071 & 0.383 \\
Species $\times$ month & 4 & 3450.909 & 864.977 & 21.333 & 0.0001 \\
Hour $\times$ month & 12 & 689.849 & 57.487 & 1.418 & 0.154 \\
Species $\times$ hour $\times$ month & 24 & 433.684 & 18.070 & 0.446 & 0.990 \\
Error & 434 & 17596.866 & 40.546 & & \\
\hline
\end{tabular}

a day ("hour" effect, Table 3), but this pattern was consistent across the three species ("species $\times$ hour" effect, Table 3 ). For all species, abundance increased from $1000 \mathrm{~h}$ to $1300 \mathrm{~h}$ and then decreased towards $1600 \mathrm{~h}$ (Figure 5). These diurnal patterns did not change through the summer ("species $\times$ month $\times$ hour" effect, Table 3 ).

3.3. Agonistic Interactions and a Size-Dependent Competitive Hierarchy. A total of 1184 attacks, sorties, and chases between these species were tallied. All the three species were significantly more likely to "chase" conspecifics than heterospecifics (C. elisa: $\chi^{2}=175.28, \mathrm{df}=2, P<0.001 ;$ C. fasciata: $\chi^{2}=107.19$, $\mathrm{df}=2, P<0.001 ;$ C. ornata: $\left.\chi^{2}=121.83, \mathrm{df}=2, P<0.001\right)$. With respect to initiating a "sortie" from a perch to investigate a passing dragonfly, C. elisa and C. ornata were significantly more aggressive towards conspecifics and less responsive to the other two species (C. elisa: $\chi^{2}=138.53, \mathrm{df}=2, P<$ 0.001; C. ornata: $\left.\chi^{2}=23.61, \mathrm{df}=2, P<0.001\right)$. Celithemis fasciata showed no preference, initiating investigative sorties against passing dragonflies at the same rates at which these 


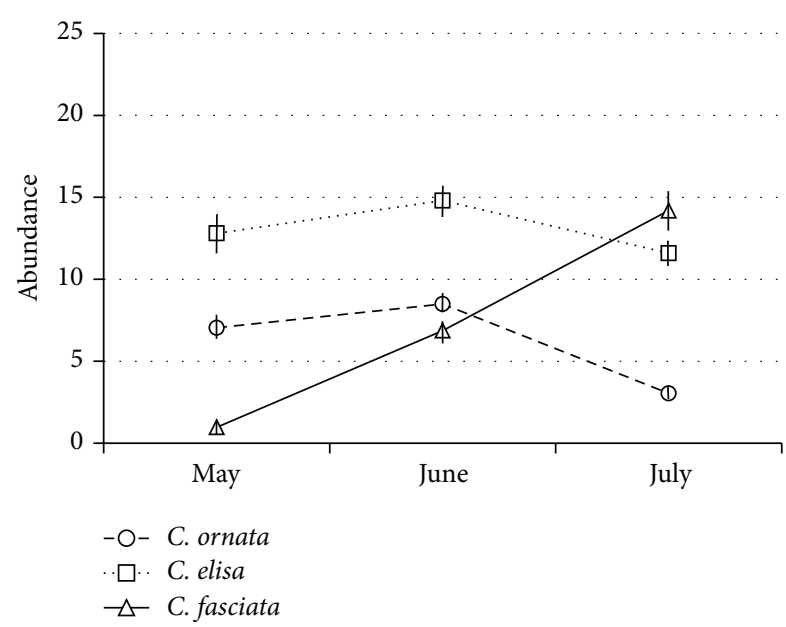

FIGURE 4: Monthly changes in the hourly abundance counts $(X \pm S E)$, for Celithemis ornata, C. elisa, and C. fasciata at Ashmore Heritage Preserve, Greenville County, SC, USA, from May to July 2015.

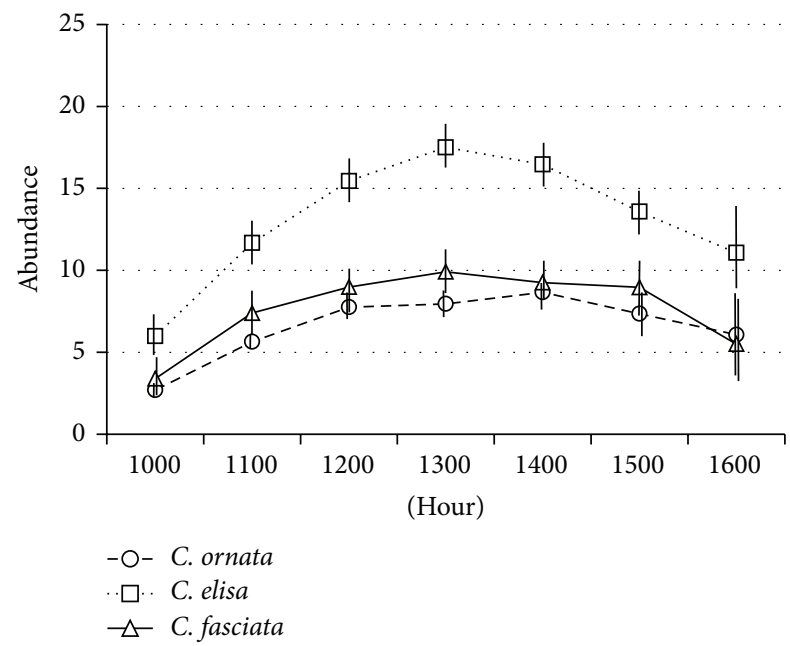

FIGURE 5: Diel changes in hourly abundance counts $(X \pm \mathrm{SE})$, averaged over the entire sampling period, for Celithemis ornata, C. elisa, and C. fasciata at Ashmore Heritage Preserve, Greenville County, SC, USA, from May to July 2015.

species occurred in the environment $\left(\chi^{2}=0.939, \mathrm{df}=2, P>\right.$ $0.05)$. When it came to attacking a perched individual, these preferences for engaging conspecifics changed: all the three species attacked C. ornata more frequently and C. fasciata less frequently than expected by their relative abundances (Figure 6).

\section{Discussion}

Although males of Celithemis elisa, C. fasciata, and C. ornata broadly overlap in size and perch use, a size-dependent competitive hierarchy influenced territorial perch selection. On average, Celithemis fasciata was significantly larger than the other two species in all five body size attributes, was avoided by both smaller species when occupying a territorial
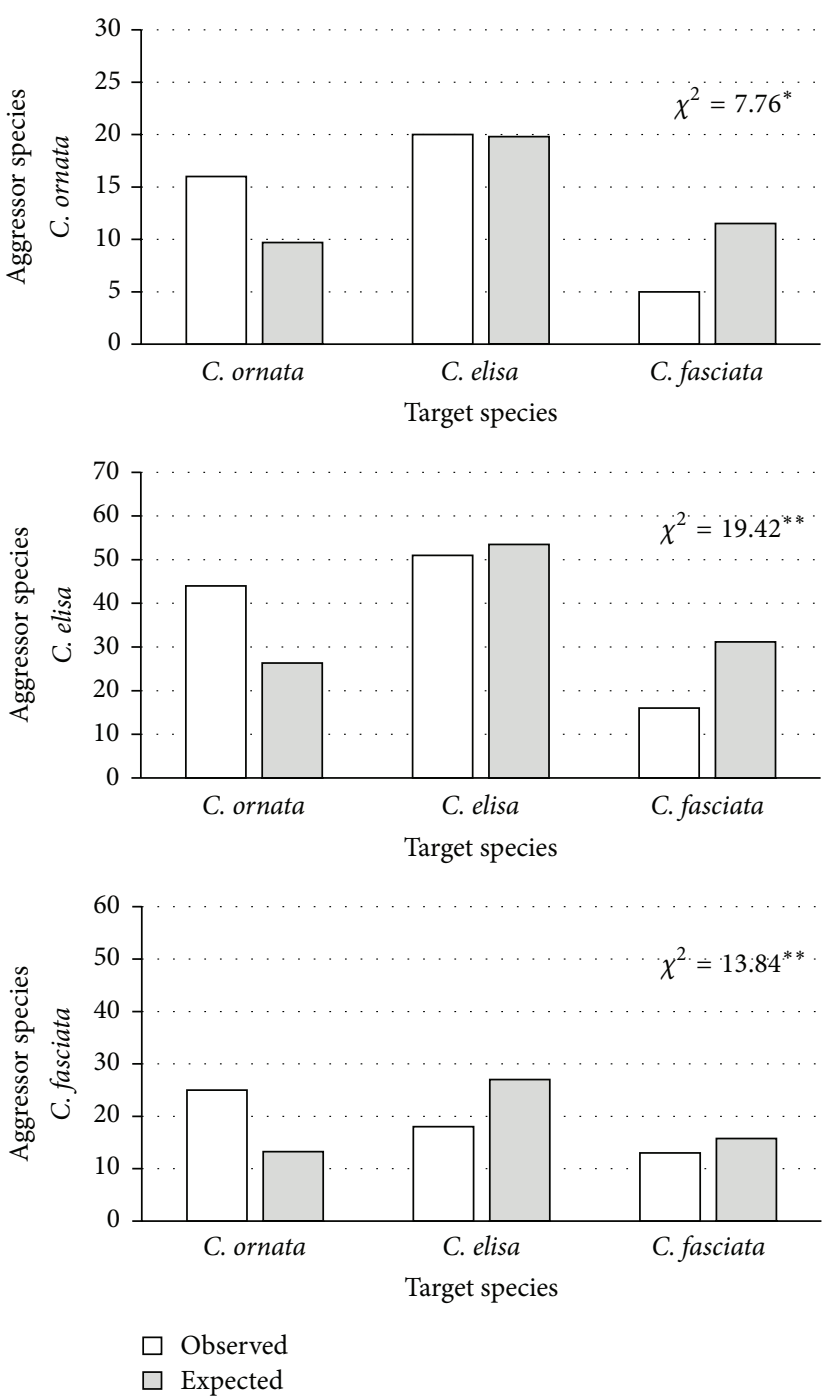

Figure 6: The frequency at which Celithemis ornata, C. elisa, and C. fasciata attacked perched individuals of these species, compared to expected frequencies based on relative mean hourly abundance counts averaged over the entire sampling period of May-July 2015 $\left({ }^{*} P<0.05 ;{ }^{* *} P<0.01\right.$, chi-squared goodness of fit tests).

perch, and used perches that were either significantly taller or closer to open water than the two smaller species. In addition, although size differences between $C$. ornata and $C$. elisa were not statistically significant, the smaller C. ornata males used significantly shorter perches than C. elisa, perched farther from the water (though not significantly farther than C. elisa), and were attacked more frequently by all species than expected by their relative abundance. In short, although all differences were not statistically significant, there were consistent rank-order patterns in perch height, perch distance, and vulnerability to attack that correspond to rank-order differences in mean body size. These patterns are consistent with the size-dependent niche partitioning of perch selection documented in other dragonfly assemblages [22-27]. 
It is illustrative to compare the results of the three aggressive behaviors. All three species preferentially chased conspecifics over the other two species, and C. elisa and C. ornata preferentially initiated sorties against conspecifics. These behaviors are typical $[4,5,15,22-24,29,43]$ and adaptive for males that hold a territory [15]; by engaging conspecifics through a sortie or chase, they can identify mature females or drive off other male suitors. For perch/territory acquisition, however, a different pattern would be expected if there were a size-dependent competitive hierarchy. Under this hypothesis, territorial males of the largest, competitively dominant species should be avoided by attacking dragonflies; even conspecific aggressors are likely to lose a competitive battle to a territorial resident $[4,16-20]$. In contrast, territorial males of the smallest, competitively subordinate species should be attacked disproportionately by all species, even by conspecifics that have a better chance against a small member of their own species than against an individual of a larger species. These were the patterns we observed: all the three species attacked the large C. fasciata less frequently and the small C. ornata more frequently than expected by their relative abundances.

An alternative hypothesis that explains differences in interspecific aggression is "mistaken identity," where morphologically similar species interact more frequently than less similar species because of imperfect species recognition cues [43-45]. Although similar in size, the Celithemis species in this study are rather different morphologically. Celithemis ornata has a reddish basal spot on the hind wings, C. elisa has reddish spots at the tip and nodus of each wing in addition to the reddish basal hindwing spot, and C. fasciata has wings that are heavily marked in black spots. If anything, it seems they have already experienced the character displacement predicted for closely related species to reduce interference competition for mates [46]. And again, although conspecifics were the focus of sorties and chases, there is a different pattern for attacking perched individuals. If mistaken identity was the cause of these interspecific behaviors, there should be the lowest error rate for attacking a stationary individual on a perch, with their wings outstretched and visible. But all species showed a nonrandom preference for attacking C. ornata and avoiding C. fasciata. These patterns are more consistent with size-dependent interspecific aggression for perch acquisition than mistaken identity of conspecifics.

Although gross patterns in perch selection support the hypothesis of a size-dependent hierarchy between these species, there was considerable variability in every metric. First, there was broad overlap in the size ranges of these species, such that large $C$. ornata were larger than small $C$. elisa and nearly equal in size to small C. fasciata. Likewise, all three species used perches between 10 and $90 \mathrm{~cm}$ in height, from the shoreline to open water. So, although these patterns hold when means are compared at the species level, individual body size may be a better predictor of competitive ability than species identity. There were also significant temporal changes in the characteristics of the perches used by each species. Mean perch height increased through the summer for all species, probably as a consequence of the growth of vegetation. However, mean perch height of $C$. elisa increased more dramatically than for the other two species. Indeed, in June, C. elisa had a significantly higher perch height than the larger $C$. fasciata. Patterns in the distance from open water of perches used by these species also changed. Although $C$. ornata used perches farthest from open water in May, this species perched closer to open water than the other two species in July. As summer progresses and vegetation grows, it becomes more difficult to see open water from short, distant perches. C. ornata males might shift to taller perches closer to open water to procure a mate, even if it means tolerating more harassment from larger, competitively superior species.

The presence of species-specific temporal patterns varied with temporal scale. As in Sympetrum danae and S. pedemontanum [32], there was no evidence of temporal partitioning by diel activity; all the three Celithemis species increased in abundance from $1000 \mathrm{~h}$ to $1300 \mathrm{~h}$ and then declined to $1600 \mathrm{~h}$. There were, however, significant differences in abundance through the sampling period: C. elisa was abundant throughout, $C$. ornata is an early-season species that began to decline in July, and C. fasciata is a late-season species that rose dramatically in July. These trends are consistent with the flight dates listed by Beaton [30]. Although there were significant differences in seasonal abundance patterns, these species coexist through the majority of their flight seasons and, during this period, tend to partition perches spatially rather than temporally.

\section{Conclusion}

Body size is a critical variable that affects and responds to competitive interactions in ecological communities [1-3]. In many communities of perching dragonflies, species partition perches based on perch height [22-27]. As a consequence of a size-dependent competitive hierarchy, larger species use taller perches and relegate progressively smaller species to progressively shorter perches [25-27]. This study documents the same pattern on a smaller scale, among three Celithemis species that are very similar in size. In addition, larger species perched closer to open water, which also may represent competitive dominance for a high-quality resource. These patterns were weak, however, and changed over the summer, perhaps as other variables became more important than these slight differences in body size or as species responded to changes in the relative quality of perches.

\section{Competing Interests}

The authors declare that there is no conflict of interests regarding the publication of this paper.

\section{Acknowledgments}

The authors thank the South Carolina Department of Natural Resources for allowing them to use the Ashmore Heritage Preserve for this research. This research was supported by Furman University through a Furman Advantage Grant to Parker H. Morrow and a Furman Standard Grant to Wade B. Worthen. 


\section{References}

[1] R. H. Peters, The Ecological Implications of Body Size, Cambridge University Press, Cambridge, UK, 1986.

[2] J. T. Bonner, Why Size Matters: From Bacteria to Blue Whales, Princeton University Press, Princeton, NJ, USA, 2006.

[3] P. R. Martin and C. K. Ghalambor, "When David beats goliath: the advantage of large size in interspecific aggressive contests declines over evolutionary time," PLoS ONE, vol. 9, no. 9, Article ID e108741, 2014.

[4] P. S. Corbet, Dragonflies: Behavior and Ecology of Odonata, Cornell University Press, Ithaca, NY, USA, 1999.

[5] M. J. Parr, "An analysis of territoriality in libellulid dragonflies (Anisoptera: Libellulidae)," Odonatologica, vol. 12, no. 1, pp. 3957, 1983.

[6] L. L. Wolf, E. C. Waltz, D. Klockowski, and K. Wakeley, "Influences on variation in territorial tenures of male white-faced dragonflies (Leucorrhinia intacta) (Odonata: Libellulidae)," Journal of Insect Behavior, vol. 10, no. 1, pp. 31-47, 1997.

[7] P. V. Switzer, "Individual variation in the duration of territory occupation in males of the dragonfly Perithemis tenera (Odonata: Libellulidae)," Annals of the Entomological Society of America, vol. 95, no. 5, pp. 628-636, 2002.

[8] J. B. Irusta and A. Araújo, "Reproductive tactics of sexes and fitness in the dragonfly, Diastatops obscura," Journal of Insect Science, vol. 7, no. 24, pp. 1-10, 2007.

[9] S. J. McCauley, "Body size and social dominance influence breeding dispersal in male Pachydiplax longipennis (Odonata)," Ecological Entomology, vol. 35, no. 3, pp. 377-385, 2010.

[10] Y. Tsubaki and T. Ono, "Effects of age and body size on the male territorial system of the dragonfly, Nannophya pygmaea rambur (Odonata: Libellulidae)," Animal Behaviour, vol. 35, no. 2, pp. 518-525, 1987.

[11] N. Sokolovska, L. Rowe, and F. Johansson, "Fitness and body size in mature odonates," Ecological Entomology, vol. 25, no. 2, pp. 239-248, 2000.

[12] D. J. Thompson and O. M. Fincke, "Body size and fitness in Odonata, stabilising selection and a meta-analysis too far?" Ecological Entomology, vol. 27, no. 3, pp. 378-384, 2002.

[13] M. A. Serrano-Meneses, A. Córdoba-Aguilar, V. Méndez, S. J. Layen, and T. Székely, "Sexual size dimorphism in the American rubyspot: male body size predicts male competition and mating success," Animal Behaviour, vol. 73, no. 6, pp. 987-997, 2007.

[14] R. Guillermo-Ferreira and K. Del-Claro, "Territoriality and male-biased sexual size dimorphism in Argia reclusa (Odonata: Zygoptera)," Acta Ethologica, vol. 15, no. 1, pp. 101-105, 2012.

[15] J. Suhonen, M. J. Rantala, and J. Honkavaara, "Territoriality in odonates," in Dragonflies and Damselflies: Model Organisms for Ecological and Evolutionary Research, A. Cordoba-Aguilar, Ed., pp. 203-218, Oxford University Press, Oxford, UK, 2008.

[16] J. K. Waage, "Confusion over residency and the escalation of damselfly territorial disputes," Animal Behaviour, vol. 36, no. 2, pp. 586-595, 1988.

[17] S. D. Gribbin and D. J. Thompson, "The effects of size and residency on territorial disputes and short-term mating success in the damselfly Pyrrhosoma nymphula (Sulzer) (Zygoptera: Coenagrionidae)," Animal Behaviour, vol. 41, no. 4, pp. 689-695, 1991.

[18] E. Kasuya, K. Edanami, and I. Ohno, "Territorial conflicts in males of the dragonfly, Orthetrum japonicum japonicum (Odonata: Libellulidae): the role of body size," Zoological Science, vol. 14, no. 3, pp. 505-509, 1997.
[19] D. J. Kemp and C. Wiklund, "Residency effects in animal contests," Proceedings of the Royal Society B: Biological Sciences, vol. 271, no. 1549, pp. 1707-1711, 2004.

[20] P. V. Switzer, "Fighting behavior and prior residency advantage in the territorial dragonfly, Perithemis tenera," Ethology Ecology and Evolution, vol. 16, no. 1, pp. 71-89, 2004.

[21] P. V. Switzer and W. Walters, "Choice of lookout posts by territorial amberwing dragonflies, Perithemis tenera (Anisoptera: Libellulidae)," Journal of Insect Behavior, vol. 12, no. 3, pp. 385398, 1999.

[22] N. W. Moore, “The development of dragonfly communities and the consequences of territorial behavior: a 27-year study on small ponds at Woodwalton Fen, Cambridgeshire, United Kingdom,” Odonatologica, vol. 20, no. 2, pp. 203-231, 1991.

[23] R. G. Warren, "Territorial behaviour of Libellula quadrimaculata L. and Leucorrhinia dubia Van der L. (Odonata: Libellulidae)," The Entomologist, vol. 97, p. 147, 1964.

[24] C. E. Williams, "Neurocordulia (Platycordulia) xanthosoma (Williamson) in Texas (Odonata: Libellulidae: Corduliiinae)," Great Lakes Entomologist, vol. 9, no. 1, pp. 63-73, 1976.

[25] W. B. Worthen and E. R. Patrick, "Competitive interactions affect perch-height preferences of three Odonata taxa (Coenagrionidae, Libellulidae)," International Journal of Odonatology, vol. 7, no. 3, pp. 529-541, 2004.

[26] W. B. Worthen and C. M. Jones, "Relationships between body size, wing morphology, and perch height selection in a guild of Libellulidae species (Odonata)," International Journal of Odonatology, vol. 9, no. 2, pp. 235-250, 2006.

[27] W. B. Worthen and C. M. Jones, "The effects of wind speed, competition, and body size on perch height selection in a guild of Libellulidae species (Odonata)," International Journal of Odonatology, vol. 10, no. 2, pp. 257-272, 2007.

[28] G. E. Rehfeldt and H. Hadrys, "Interspecific competition in sympatric Sympetrum sanguineum (Müller) and S. flaveolum (L.) (Anisoptera: Libellulidae)," Odonatologica, vol. 17, no. 3, pp. 213-225, 1988.

[29] D. C. Resende, "Residence advantage in heterospecific territorial disputes of Erythrodiplax Brauer species (Odonata, Libellulidae)," Revista Brasileira de Entomologia, vol. 54, no. 1, pp. 110-114, 2010.

[30] G. Beaton, Dragonflies and Damselflies of Georgia and the Southeast, University of Georgia Press, Athens, Ga, USA, 2007.

[31] M. L. May, "Thermoregulation and reproductive activity in tropical dragonflies of the genus Micrathyria," Ecology, vol. 58, no. 4, pp. 787-798, 1977.

[32] N. K. Michiels and A. A. Dhondt, "Coexistence of three Sympetrum species at Den Diel, Mol, Belgium (Anisoptera: Libellulidae)," Odonatologica, vol. 16, no. 4, pp. 347-360, 1987.

[33] R. Khelifa, R. Zebsa, A. Moussaoui, A. Kahalerras, S. Bensouilah, and H. Mahdjoub, "Niche partitioning in three sympatric congeneric species of dragonfly, Orthetrum chrysostigma, $O$. coerulescens anceps, and $O$. nitidinerve: the importance of microhabitat," Journal of Insect Science, vol. 13, article 71, pp. 117,2013

[34] D. Paulson, Dragonflies and Damselflies of the East, Princeton University Press, Princeton, NJ, USA, 2011.

[35] S. W. Dunkle, Dragonflies through Binoculars, Oxford University Press, Oxford, UK, 2000.

[36] W. H. Cross, "Anisopteran odonata of the Savannah River Plant, South Carolina," Journal of the Elisha Mitchell Scientific Society, vol. 71, no. 1, pp. 9-17, 1955. 
[37] J. H. Kaufmann, "On the definitions and functions of dominance and territoriality," Biological Reviews, vol. 58, no. 1, pp. 1-20, 1983.

[38] South Carolina Department of Natural Resources, "Ashmore Heritage Preserve/Wildlife Management Area," 2007, https:// www2.dnr.sc.gov/ManagedLands/ManagedLand/ManagedLand/1.

[39] W. B. Worthen and L. H. Turner, "The effects of odonate species abundance and diversity on parasitism by water mites (Arrenurus spp.): Testing the dilution effect," International Journal of Odonatology, vol. 18, no. 3, pp. 233-248, 2015.

[40] K. Higashi and T. Uéda, "Territoriality and movement pattern in a population of Calopteryx cornelia (Selys) (Zygoptera: Calopterygidae)," Odonatologica, vol. 11, no. 2, pp. 129-137, 1982.

[41] W. S. Rasband, ImageJ, US National Institutes of Health, Bethesda, Md, USA, 2015, http://imagej.nih.gov/ij/.

[42] IBM Corporation, IBM SPSS Statistics for Windows-Version 21.0, IBM Corporation, Armonk, NY, USA, 2012.

[43] W. B. Worthen and C. C. Phillips, "Are community patterns in flight height driven by antagonistic interactions?" International Journal of Odonatology, vol. 17, no. 1, pp. 7-16, 2014.

[44] J. K. Schultz and P. V. Switzer, "Pursuit of heterospecific targets by territorial amberwing dragonflies (Perithemis tenera Say): a case of mistaken identity," Journal of Insect Behavior, vol. 14, no. 5, pp. 607-620, 2001.

[45] K. Tynkkynen, M. J. Rantala, and J. Suhonen, "Interspecific aggression and character displacement in the damselfly Calopteryx splendens," Journal of Evolutionary Biology, vol. 17, no. 4, pp. 759-767, 2004.

[46] J. P. Drury, K. W. Okamoto, C. N. Anderson, and G. F. Grether, "Reproductive interference explains persistence of aggression between species," Proceedings of the Royal Society of London Series B: Biological Sciences, vol. 282, no. 1804, Article ID 20142256, 2015. 

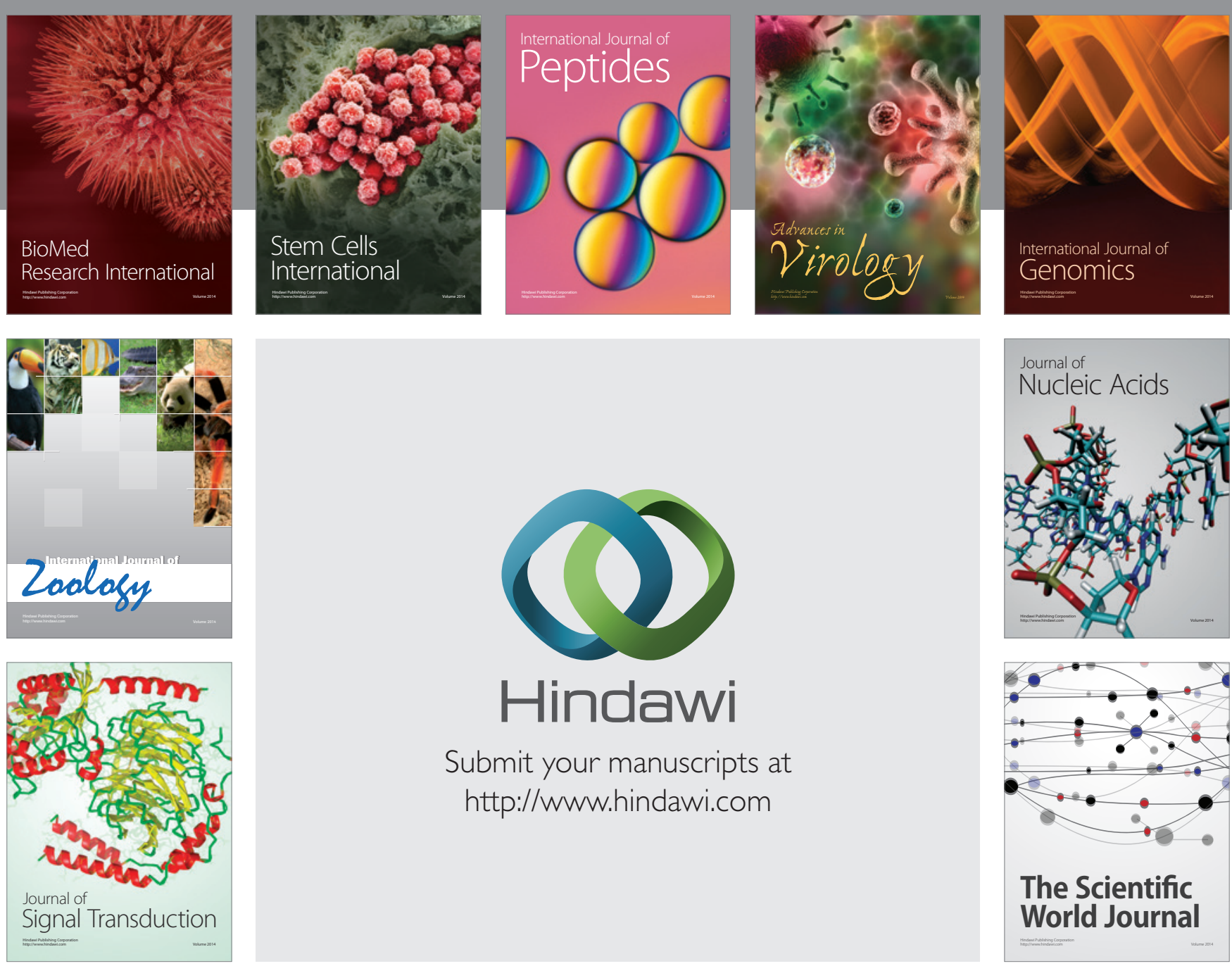

Submit your manuscripts at

http://www.hindawi.com
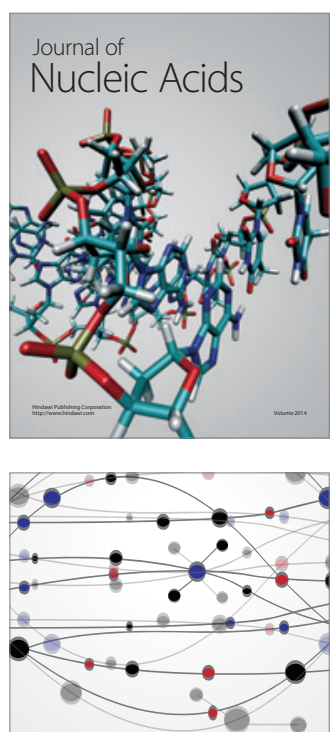

The Scientific World Journal
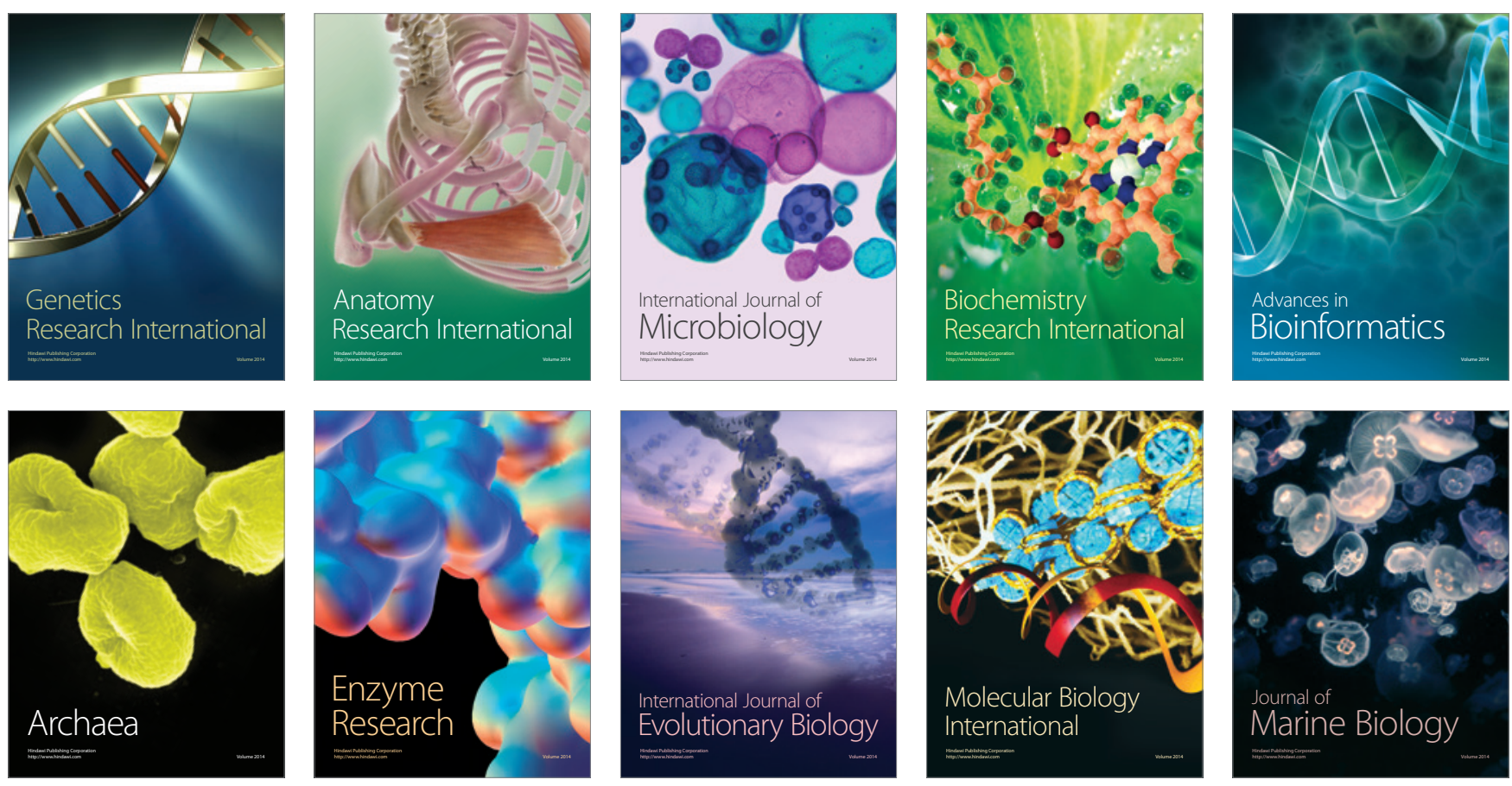